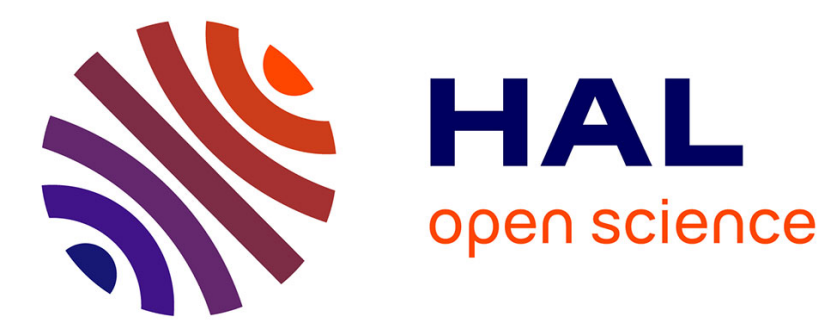

\title{
New approach for the quantification of processed animal proteins in feed using light microscopy
}

Pascal Veys, Vincent Baeten

\section{To cite this version:}

Pascal Veys, Vincent Baeten. New approach for the quantification of processed animal proteins in feed using light microscopy. Food Additives and Contaminants, 2010, 27 (07), pp.926-934. 10.1080/19440041003671296 . hal-00598955

\section{HAL Id: hal-00598955 https://hal.science/hal-00598955}

Submitted on 8 Jun 2011

HAL is a multi-disciplinary open access archive for the deposit and dissemination of scientific research documents, whether they are published or not. The documents may come from teaching and research institutions in France or abroad, or from public or private research centers.
L'archive ouverte pluridisciplinaire HAL, est destinée au dépôt et à la diffusion de documents scientifiques de niveau recherche, publiés ou non, émanant des établissements d'enseignement et de recherche français ou étrangers, des laboratoires publics ou privés. 


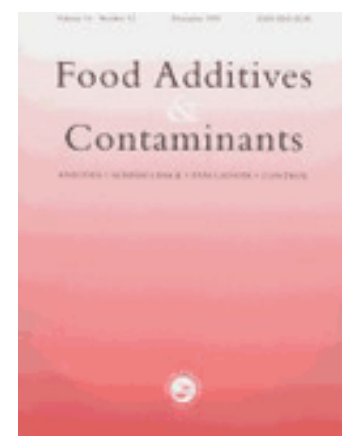

\section{New approach for the quantification of processed animal proteins in feed using light microscopy}

\begin{tabular}{|r|l|}
\hline Journal: & Food Additives and Contaminants \\
\hline Manuscript ID: & TFAC-2009-410.R1 \\
\hline Manuscript Type: & Original Research Paper \\
\hline $\begin{array}{r}\text { Date Submitted by the } \\
\text { Author: }\end{array}$ & 21-Jan-2010 \\
\hline Complete List of Authors: & $\begin{array}{l}\text { Veys, Pascal; Walloon Agricultural Research Center } \\
\text { Baeten, Vincent; Walloon Agricultural Research Center }\end{array}$ \\
\hline Methods/Techniques: & In-house validation, Method validation \\
\hline Additives/Contaminants: & Animal products, Feeding \\
\hline Food Types: & Animal feed, Animal feedingstuffs \\
\hline &
\end{tabular}

\section{SCHOLARONE ${ }^{\text {M }}$ \\ Manuscripts}




\section{New approach for the quantification of processed animal}

2 proteins in feed using light microscopy

3

$4 \quad$ P. Veys ${ }^{*}$ and V. Baeten

5

6 Walloon Agricultural Research Centre CRA-W, Chaussée de Namur 24, 5030 Gembloux,

7 Belgium

*Corresponding author. Email: p.veys@cra.wallonie.be 
8

9

\section{Abstract}

A revision of European Union's total feed ban on animal proteins in feed will need robust quantification methods, especially for control analyses, if tolerance levels are to be introduced, as for fishmeal in ruminant feed. In 2006, a study conducted by the Community Reference Laboratory for Animal Proteins in feedstuffs (CRL-AP) demonstrated the deficiency of the official quantification method based on light microscopy. The study concluded that the method had to be revised. This paper puts forward an improved quantification method based on three elements: (1) the preparation of permanent slides with an optical adhesive preserving all morphological markers of bones necessary for accurate identification and precision counting, (2) the use of a counting grid eyepiece reticle and (3) new definitions for correction factors for the estimated portions of animal particles in the sediment. This revised quantification method was tested on feeds adulterated at different levels with bovine meat and bone meal (MBM) and fishmeal, and it proved to be effortless to apply. The results obtained were very close to the expected values of contamination levels for both types of adulteration (MBM or fishmeal). Calculated values were not only replicable, but also reproducible. The advantages of the new approach, including the benefits of the optical adhesive used for permanent slide mounting and the experimental conditions that need to be met to implement the new method correctly, are discussed.

Keywords: BSE; PAP; animal proteins; quantification; meat and bone meal; fishmeal 


\section{Introduction}

Since 1 January 2001, the European Union has forbidden the use of processed animal proteins in feed for animals bred for food production. Because of the decrease in the number of diagnosed cases of bovine spongiform encephalopathy (BSE) that has been observed thanks to the drastic risk reduction measures at the European level, on 15 July 2005 the European Commission adopted a checklist for the transmissible spongiform encephalopathies. This document, known as "The TSE Roadmap" (European Commission 2005), presents modifications that could be applied to the measures for BSE while continuing to give high priority to food safety and consumer protection. One of the objectives is to soften, under well-defined conditions, the impact of the current total ban of animal proteins. Among the various possibilities is the introduction of a tolerance level for the presence of fishmeal in ruminant feeds, as this presence may originate from an indirect crosscontamination from fishmeal-containing feed for non-ruminants. A revision of the current feed ban could start only when adequate control methods are in place to ensure the correct implementation of this feed ban. In this respect, such tolerance level would necessitate a reliable method of quantifying fishmeal content. The only quantification method at the moment is the one described by the EC 152/2009 regulation (European Union 2009), which is the official reference to apply for determining the animal origin of feed constituents using classical light microscopy.

In 2006, an interlaboratory study conducted by the Community Reference Laboratory for Animal Proteins in feedstuffs (CRL-AP) evaluated this quantification method (Veys and Baeten 2007), which was at that time described in now repealed EC 126/2003 directive (European Union 2003). The study, involving 22 participants and 10 quantifications for fishmeal (five duplicated feed samples adulterated at levels ranging from $2.5 \mathrm{~g} \mathrm{~kg}^{-1}$ to 15 $\mathrm{g} \mathrm{kg}^{-1}$ ), not only demonstrated the shortcomings of the official quantification method, but also illustrated its inapplicability. Five participants out of 22 were unable to use the method due 
55 mainly to a lack of clear definitions of parameters such as correction factors. The study 56 highlighted the urgent need for improvements in the quantification method.

57 Although quantification is currently optional for official controls due to the total ban 58 status, it would become mandatory if a tolerance level was introduced. In view of this, the 59 objective of the present paper is to propose improvements to the light microscopy-based 60 method of quantification. The improvements are (1) an adequate mounting medium allowing 61 permanent slide preparations, (2) a counting process supported by a counting grid eyepiece 62 reticle and (3) a detailed definition of the correction factors for the estimated portions of 63 animal bones - and scale fragments - in the sediment. 


\section{Material and Methods}

\section{Sample material}

A typical compound feed for bovine was used. It contained wheat, corn, soybean, palm kernel meal, coconut meal, beet pulp, sunflower seeds, straw, molasses, salts and vitamins. The feed had a sediment of $11 \mathrm{~g} \mathrm{~kg}^{-1}$ after settling by tetrachloroethylene (TCE). In order to ensure homogeneity, the feed was adulterated by a stepwise dilution (Gizzi et al. 2004) at 10 $\mathrm{g} \mathrm{kg}^{-1}$ and $5 \mathrm{~g} \mathrm{~kg}^{-1}$ with bovine meat and bone meal (MBM). The MBM produced by a pilot plant was treated at $133^{\circ} \mathrm{C}$ at 3 atm for $20 \mathrm{~min}$ and had a bone content of $830 \mathrm{~g} \mathrm{~kg}^{-1}$ after settling by TCE. A second feed composed of wheat, corn, soybean meal, fat of plant origin, limestone, salts, minerals and vitamins, and with a sediment of $22 \mathrm{~g} \mathrm{~kg}^{-1}$ was also used. This second feed was adulterated with an industrial fishmeal at $10 \mathrm{~g} \mathrm{~kg}^{-1}$ and $4 \mathrm{~g} \mathrm{~kg}^{-1}$ by a stepwise dilution. The fishbone content of the fishmeal was $120 \mathrm{~g} \mathrm{~kg}^{-1}$.

\section{Sediment preparation and staining}

The sample material was prepared according to EC 152/2009 regulation (European Union, 2009). General principles of preparation may be resumed as follows. Samples undergo first settling by TCE (density $1.62 \mathrm{~g} \mathrm{ml}^{-1}$ ) in order to concentrate the particles of higher density (i.e. bones, cartilage, minerals) into a sediment whereas the light density material (i.e. plant material, muscle fibers) is separated. Detection of processed animal proteins (PAPs) is performed on both sediment and raw material which are sieved in order to obtain respectively fine and coarse fractions. Analyses are finally performed by stereomicroscope on the coarse fractions and by light microscope on the fine fractions.

As stated in the EC 152/2009 regulation (European Union, 2009), quantification can be done only if the constituents of animal origin contain bone fragments. It can therefore be done only on the sediment fraction obtained from the sample material after sedimentation with TCE. 
The sedimentation was carried out with $10 \mathrm{~g}$ (accurate at $0.01 \mathrm{~g}$ ) of sample material $(W)$. The recovered sediment was dried in the oven at $50-90^{\circ} \mathrm{C}$. It was then weighed (unstained sediment weight, $S$ ) at a precision of $1 \mathrm{mg}$ and stained with Alizarin Red solution. The stained sediment was allowed to dry and was then weighed (stained sediment weight, Ss) at a precision of $1 \mathrm{mg}$. Having obtained Ss, the sediment was sieved using a $250 \mu \mathrm{m}$ mesh sieve. The two sediment fractions obtained, fine $(<250 \mu \mathrm{m})$ and coarse $(>250 \mu \mathrm{m})$, were mounted separately on microscope slides. Classical slides were used for the fine sieved fraction and hollow slides for the coarse fraction.

\section{Slide mounting and observation}

Permanent microscope slides were prepared with Norland Optical Adhesive 65 (Norland Products, Cranbury, USA) which has a viscosity of $1200 \mathrm{cps}$ at $25^{\circ} \mathrm{C}$, refractive index after curing $n=1.524$. A few drops of resin were poured onto a slide, and then some sediment was put on the resin using a spatula. The sediment was gently stirred to spread it uniformly over the resin deposit and then a coverglass was immediately placed on the slide, which was directly placed for curing under a UV source at $365 \mathrm{~nm}$ for at least 2 minutes.

The slides were examined using a Carl Zeiss Axio Imager A1 under conventional transmitted bright-field light microscopy. All countings were done at a magnification of 100x.

\section{Grid counting}

\section{Grid type}

An eyepiece reticle with an engraved grid known as Counting Pattern NG14 (Pyser-SGI Ltd, Edenbridge, UK) was used. The grid had $10 \times 10$ crosses in a $100 \mu \mathrm{m}$ mesh over an area of 1 $\mathrm{mm}^{2}$. This grid is a suitable geometrical probe for point counting, the appropriate stereological method for considering volume fractions, as recommended by Howard and Reed (2005). 
113

114

115

116

117

118

119

120

121

122

123

124

125

126

127

128

129

130

131

132

133

134

135

136

137

\section{Counting method}

The quantification was based on point counting (Russ 2005; Howard and Reed 2005) and carried out as described here.

The counting area was the grid square with the crosses (Figure 1); the remaining part of the field was not taken into consideration. Depending on the need for a dimensionless reference (Howard and Reed 2005) for point counting, a zero-dimension point was associated with each cross on the grid (Figure 1). This required close examination using the correct Kölher illumination (i.e. proper alignment of incident light by adjustment of the condenser height) and a sharp focus on each particle limit before deciding whether a cross hit could be considered.

Various numbers (cf. Experiments sub-section) of randomized fields per slide were used for grid counting. In order to achieve randomization, the fields were selected blind by going through a slide along the $X$ and $Y$ axes without looking into the eyepieces. For each field, the following counts were reported: the number of fish particle counts $(F c)$, the number of terrestrial animal particle counts $(T C)$ and the number of particle counts from other nature (Oc). The randomized fields without any particles were not considered as effectively only ratios from one type of counts over the others are relevant. Theoretical relative precision of grid counting (over all fields of all slides), expressed in percent, was estimated by the following formula deduced from Russ (2005):

$$
\%=\left(1-\frac{\sqrt{N \times \bar{m}_{\text {counts Ifields }}}}{\sum_{\text {field }=1}^{N} \text { counts }_{\text {field }}}\right) \times 100
$$

Where $N$ is the number of fields observed, $\bar{m}_{\text {counts/fields }}$ is the average number of total particle counts (bones and others) per field. Figure 2 illustrates the influence of the number of fields and the average number of total counts on the final relative precision of the counting. As a rule the average number of total particle counts (bones and others) per field was decided to be fixed above a mean of 25. According to Russ (2005) special attention was 
138 taken to insure independence of sample probing. Hence in order to reach the adequate 139 number of fields allowing an appropriate relative counting precision, the following strategy 140 was used. As from stained sediment only a minute amount of material is required for 141 preparing a slide, it was chosen to increase the number of slides while keeping the number 142 of random fields per slide limited. This forced the analysts to observe a more representative 143 fraction of the sediment. This was preferred upon the option of increasing the number of 144 fields per slide up to reaching an acceptable level of relative counting precision but on a 145 biased sample sub-fraction.

\section{Quantification formula}

147 The formulae for the estimated constituents of animal constituents were revised versions of 148 the formulae described in the EC 152/2009 regulation.

The first computation required was the estimation of the portion of terrestrial bones 150 (or fish bones and scale fragments) in the stained sediment (the $c$ or $d$ factors, respectively). 151 The formulae used for estimating the $c$ and $d$ factors were based on the number of different 152 types of counts measured over all slides:

$$
\begin{gathered}
c=\frac{T c}{T c+F c+O c}=\frac{T c}{\Sigma \text { all counts }} \\
d=\frac{F c}{T c+F c+O c}=\frac{F c}{\Sigma \text { all counts }}
\end{gathered}
$$

The formulae used for the estimated value of constituents of animal origin of the sample were: 
Where $W$ is the weight of the sample material used for the sedimentation, $S s$ is the weight of the stained sediment, and $f$ is a correction factor for the proportion of bones in the constituents of animal origin in the sample examined as defined in EC 152/2009. As recommended at the first CRL-AP 2006 workshop intended for the European network of National Reference Laboratories (April 2007, Gembloux, Belgium), the values of $f$ were fixed at 0.10 for fish and 0.40 for terrestrial.

\section{Experiments}

Two successive experiments were realised. For each experiment, two analysts conducted quantifications on the same slides, without knowing each other's results.

A first experiment for testing the quantification method was initially implemented on feeds fortified with bovine MBM at $5 \mathrm{~g} \mathrm{~kg}^{-1}$ and $10 \mathrm{~g} \mathrm{~kg}^{-1}$. For this experiment, six permanent slides were prepared, three each from the fine and the coarse fractions of the stained sediment. On each slide only five fields were counted, once. Thus a grand total of 30 fields were counted for estimating $c$. The quantification was repeated on five replicates of each material.

A second experiment was undertaken on a feed adulterated with fishmeal at $4 \mathrm{~g} \mathrm{~kg}^{-}$ ${ }^{1}$ and $10 \mathrm{~g} \mathrm{~kg}^{-1}$. This time a higher relative precision of counting was desired in order to determine its influence on the final quantification of PAPs. For that reason permanent slides were prepared from both fine and coarse fractions but using the whole sediment. This allowed obtaining 8-10 slides from each sediment. On each slide six fields were counted. The counting was repeated three times on different days. The counting for the estimation of $d$ resulted from a total of 18 fields per slide pooled together - thus a grand total of $144-180$ fields. The quantification was repeated on five replicates of each material.

\section{Statistical analysis}

As recommended by Feinberg (2006) analyses of variance, with one classification criteria, have been applied to check if statistical significant differences or trends could be detected 
187 between analysts. The analyst (ANA) corresponded to the factor studied and significance 188 was declared if $\mathrm{P}<0.05$ and trends expressed if $\mathrm{P}<0.10$.

189 Variance components between analysts and error variance components have been 190 estimated, from these analyses of variance, to evaluate repeatability $(r)$ and intralaboratory 191 reproducibility - or intermediate precision (R) (ISO 5725-2). Standard deviation of 192 repeatability $\left(\mathrm{S}_{\mathrm{r}}\right)$ is equal to the square root of the error mean square $\left(\mathrm{MS}_{\text {error }}\right)$ : Variance component of analyst $\left(s_{\mathrm{ANA}}^{2}\right)$ is equal to

$$
S_{\text {ANA }}^{2}=\frac{\left(\mathrm{MS}_{\mathrm{ANA}}-\mathrm{MS}_{\text {error }}\right)}{\mathrm{n}}
$$

where $\mathrm{MS}_{\mathrm{ANA}}$ is the mean square among analysts and $\mathrm{n}$ the number of replicates.

197 Standard deviation of reproducibility $\left(S_{R}\right)$ is equal to the square root of the analyst 198 and error variance $\left(S^{2}\right.$ error $)$ components:

$199 S_{R}=\sqrt{s_{\text {ANA }}^{2}+s_{\text {error }}^{2}}$ and intralaboratory reproducibility, at $\mathrm{P}=0.05$, is equal to $\boldsymbol{R}=\mathbf{1 . 9 6} \times \sqrt{\mathbf{2}} \times \boldsymbol{s}_{\boldsymbol{R}}$ 200 For comparative purpose with results from Veys and Baeten (2007), relative 201 standard deviations for the repeatability $\left(R S D_{r}\right)$ and intralaboratory reproducibility $\left(R_{S D_{R}}\right)$ 202 were calculated according to McClure and Lee (2003). 
203

204

205

206

207

208

209

210

211

212

213

214

215

216

217

218

219

220

221

222

223

224

225

226

227

228

\section{Results}

\section{Permanent slide preparation}

The viscosity of the Norland Optical Adhesive 65 at room temperature is almost equivalent to that of pure glycerol (ca. $1490 \mathrm{cps}$ ) which is one of the mounting media recommended in EC $152 / 2009$ regulation. This high viscosity prevents the mounting medium from entering the lacunae of the osteocytes. These appeared as mostly black structures when observed under a bright field microscope and thus facilitated the diagnosis of the bone fragments (Figure 3 ). The resin also preserved the visualisation of the faint network of canaliculi (Figure 3, arrowheads) which usually fade over time when mounted using glycerol or paraffin oil (Figures 4A and 4B). The UV curing process was rapid and did not generate a noteworthy transient decrease in viscosity that would have allowed the resin to penetrate the bone lacunae. The prepared slides were permanent and could be stored in boxes. No alteration such as resin shrinking, development of air bubbles, or modification of the colour of the stained particles was observed over a 12-month period. In addition, the Norland Optical Adhesive 65 remained colourless and totally transparent and isotropic.

\section{Quantification}

Data of the first experiment are summarized in Table 1.

For both adulterated feeds, the means of calculated MBM contents were close to the expected values of $5 \mathrm{~g} \mathrm{~kg}^{-1}$ and $10 \mathrm{~g} \mathrm{~kg}^{-1}$. The observed standard errors of the mean (SEM) were all in the same range (from $0.59 \mathrm{mg} \mathrm{g}^{-1}$ to $0.81 \mathrm{mg} \mathrm{g}^{-1}$ ). Apart from the $5 \mathrm{~g} \mathrm{~kg}^{-1}$ MBM content from analyst 1 , the coefficients of variation (CV) for both adulterated feeds were below 30\%. The CV were higher for the $5 \mathrm{~g} \mathrm{~kg}^{-1} \mathrm{MBM}$ feed (22.48\% and $\left.32.03 \%\right)$ than for the $10 \mathrm{~g} \mathrm{~kg}^{-1}$ MBM feed (15.08\% and 20.74\%). Compared to target values, a slight overestimation was observed for the $5 \mathrm{~g} \mathrm{~kg}^{-1}$ MBM containing feed while a slight underestimation was observed for the other feed. The analyses of variance (Table 3) on the MBM contents demonstrated that no statistical significant differences or trends could be 
detected between analysts. This held true for both MBM containing feeds. The values for the repeatability $(r)$ and the intralaboratory reproducibility $(R)$ for the MBM content (Table 3 ) confirmed that the component of variance was mainly residual rather than linked to differences between analysts ( $r=R$ for $5 \mathrm{~g} \mathrm{~kg}^{-1} \mathrm{MBM}$ and $\mathrm{r}=0.85 \mathrm{R}$ for $10 \mathrm{~g} \mathrm{~kg}^{-1} \mathrm{MBM}$ ).

The mean amount of stained sediment recovered from the weight of the sample material $\left(S s / W\right.$ ) ranged from 7.53 to $8.28 \mathrm{mg} \mathrm{g}^{-1}$ and showed CV inferior to $15 \%$ for both adulterated feeds.

The $c$ values showed CV inferior to $30 \%$ for both MBM contents. For a same level of MBM adulteration no significant differences or trends between analysts could be detected for the $c$ values (Table3). This was confirmed by the repeatability and intralaboratory reproducibility found for $c$ values. $R$ and $r$ were almost equals $\left(r=R\right.$ for $5 \mathrm{~g} \mathrm{~kg}^{-1} \mathrm{MBM}$ and $r=0.83 \mathrm{R}$ for $\left.10 \mathrm{~g} \mathrm{~kg}^{-1} \mathrm{MBM}\right)$ thus illustrating the absence of differences among analysts.

The data of the second experiment with fish adulterated feeds are summarized in Table 2.

The mean calculated fish contents were close to the expected values of $4 \mathrm{~g} \mathrm{~kg}^{-1}$ and $10 \mathrm{~g} \mathrm{~kg}^{-1}$. Excluding $4 \mathrm{~g} \mathrm{~kg}^{-1}$ fish from analyst 1, a slight overall underestimation was observed for both percentages of adulteration. With the exception of $10 \mathrm{~g} \mathrm{~kg}^{-1}$ fish content from analyst 2, SEM were in the same range (from $0.28 \mathrm{mg} \mathrm{g}^{-1}$ to $0.44 \mathrm{mg} \mathrm{g}^{-1}$ ). In no cases CV for the calculated fish contents exceeded $30 \%$. Higher values of CV were observed for analyst 2 for both fish content estimations. Nevertheless only estimations of the $4 \mathrm{~g} \mathrm{~kg}^{-1}$ fish differed significantly among analysts (Table 3). Equality of repeatability and intralaboratory reproducibility (Table 3) revealed that component of variance was strictly residual for the $10 \mathrm{~g}$ $\mathrm{kg}^{-1}$ fish content. This was not the case for the $4 \mathrm{~g} \mathrm{~kg}^{-1}$ fish content: the differences between analysts impacted on the reproducibility $(r=0.48 \mathrm{R})$.

The mean amounts of stained sediment were similar $\left(16.79 \mathrm{mg} \mathrm{g}^{-1}\right.$ and $16.88 \mathrm{mg} \mathrm{g}^{-}$ $\left.{ }^{1}\right)$ for both fish-containing feeds and CV were much reduced. 
$255 \quad$ All calculated $d$ values had CV below $30 \%$. The variability of $d$ between analysts 256 (Table 3) reflected the variability observed for the mean calculated fish content: no 257 differences at $10 \mathrm{~g} \mathrm{~kg}^{-1}$ fish and significant differences at $4 \mathrm{~g} \mathrm{~kg}^{-1}$ fish. As for the estimated 258 fish content, equality of repeatability and intralaboratory reproducibility for $d$ (Table 3) was 259 noted for the $10 \mathrm{~g} \mathrm{~kg}^{-1}$ fish content while differences between analysts influenced for half of 260 the reproducibility $(r=0.50 \mathrm{R})$ for the $4 \mathrm{~g} \mathrm{~kg}^{-1}$ fish.

261

For both experiments relative standard deviations for the repeatability $\left(\mathrm{RSD}_{\mathrm{r}}\right)$ and 262 reproducibility $\left(R S D_{R}\right.$ ) were inferior to $30 \%$ (Table 4) except for the $R_{S D}$ for the $4 \mathrm{~g} \mathrm{~kg}^{-1}$ fish. 


\section{Discussion}

264 Norland Optical Adhesive 65 was shown to be very suitable for permanent slide preparation 265 from sediment material. The physical properties of the resin, such as its viscosity and its high 266 refractive index after curing, allow not only good visibility of the bone lacunae and other 267 sediment structures, but also facilitate other light microscopy analyses, such as differential 268 interferential contrast. The rapid UV curing is interesting when compared with other high 269 viscosity resins, because a great number of slides can be prepared at once and are then 270 almost immediately available for observation. This study showed the stability of Norland 271 Optical Adhesive 65 slides over time. The durability of these slides is a real advantage; for 272 example, it allows the results to be confirmed within a laboratory by different operators at 273 different times. In the case of counter analysis, the same suspect bone particles can be analyzed by different laboratories. This possibility is an added value when compared with the analyses of pictures that are limited to a single focus depth. The only minor limitation we experienced with the resin use concerned its reactivity with UV, which generates a 277 background autofluorescence when exited under fluorescence microscopy at a $\square$ of $365 \mathrm{~nm}$. 278 Finally, according to the manufacturer's data on the resin properties for spectral 279 transmission, it is possible to use the same permanent slides for analysis by infrared spectroscopy (tests are in progress). This is very attractive as it would enable the identification of the same material, even the same particles, to be made using two complementary methods. For all these reasons, this type of permanent slide mounting is strongly recommended.

Grid counting was easy to apply. Only a short adaptation period - a few hours was required before an analyst was able to start quantification by grid counting. A Köhler illumination and sharp focusing at the margins of particles are critical for accurate counting. This was so particularly for grid counting on hollow slides for the coarse $(>250 \mu \mathrm{m})$ fraction particles. Not doing this could lead to an overestimation bias (Howard and Reed 2005). Also of importance is the randomised field selection which is needed to obtain an unbiased 
290 representative sample from the sediment. According to Russ (2005), a sparse grid (10x10) 291 facilitates the counting process. However, with this grid a minimum number of fields have to 292 be examined in order to reach an acceptable level of precision, while continuing to ensure 293 probe independence (Howard and Reed 2005). Results (Figure 2) showed that 30 fields over 294 six slides were enough to get a counting precision above $96 \%$ under the defined experimental conditions. A higher counting precision (e.g. 98.5\% obtained by analysing 180 296 fields - as for the second experiment with fish adulteration) did not improve the values for $297 \mathrm{RSD}_{\mathrm{r}}$ and $\mathrm{RSD}_{\mathrm{R}}$. Analysing more fields would therefore not add useful information and 298 should not be done when the density of material on the slides enables achieving a mean of 25 counts per field. In this way, the density of material deposit is likely to be crucial: too little material would lead to an increased number of fields to count, while too much material would require difficult and inaccurate eye counting. Special attention should therefore be taken in slide preparation in order to reach the adequate balance between an acceptable amount of particles and effortless grid counting. In addition, the small sample sub-portions placed on the slides should be as representative as possible of the whole sediment. This is especially true when using the formulae for estimating $c$ and $d$. If this representative homogeneity cannot be achieved, the only alternative would be to prepare slides from the whole sediment.

The formulae used for estimating $c$ and $d$ are easy to implement as they are a simple ratio calculations: counts from a given particle nature over the sum of all counts. The values obtained for these two factors are repeatable and generally reproducible. It is worth noting that, on one exception, repeatability and intralaboratory reproducibility for $c$ (and $d$ ) were almost equals (Table 3). Thus it can be concluded that variance components for $c$ and $d$ are mainly residual and not linked to the analysts. The methods for estimating $c$ and $d$ are thus reliable. Interestingly in this study, the smallest values of CV were detected for the 314 stained sediment amounts recovered after sedimentation and staining. This was already 315 noted by Veys and Baeten (2007) who presumed that sedimentation followed by Alizarin Red 316 staining was a limited source of variability. This all indicates that the final estimation of constituents from animal origin in feed would eventually be more influenced by the estimation 
318 of $c$ and $d$ than by another factor $-f$ being fixed. For that reason, the accurate definition for 319 the computation of $c$ and $d$, as proposed in this study, is required if there is to be any 320 improvement in the quantification method based on the EC 152/2009 regulation.

Comparing the $\mathrm{RSD}_{\mathrm{R}}$ obtained in this study with those from the CRL-AP Interlaboratory Study 2006 (Veys and Baeten 2007) emphasizes the improvements supported by the present method. $\mathrm{RSD}_{\mathrm{R}}$ from the earlier study ranged from $85 \%$ (best result) to $116 \%$ (worst result) for feeds adulterated with $10 \mathrm{~g} \mathrm{~kg}^{-1}$ fish meals. Those past values of $R S D_{R}$ were calculated by robust statistics that are known to already attenuate extreme values (von Holst and Alder 2005). Based on the proposed enhancements, the current $\mathrm{RSD}_{\mathrm{R}}$ obtained without robust statistics are several-times better, even for the $4 \mathrm{~g} \mathrm{~kg}^{-1}$ fish containing feed presenting a $R S D_{R}$ of $45 \%$.

The CRL-AP Interlaboratory Study 2006 (Veys and Baeten 2007) also showed a generalised major overestimation for the final estimations of constituents of animal origin. In the present study, apart from the results for the $5 \mathrm{~g} \mathrm{~kg}^{-1}$ MBM content, no overall overestimation was demonstrated. On the contrary, a minor underestimation of the expected values is likely to be observed. However, further studies are needed to verify this hypothesis.

As a concluding remark, it must be emphasized that the proposed protocol more appropriately estimates on a well standardized way contents of PAPs in feed rather than quantifying it sensu stricto. Effectively as mentioned in EC 152/2009 regulation, the value of bone content, the $f$ factor, varies among different PAPs depending on the processing ways, but also the origin of the animal remains being used for obtaining PAPs. By fixing values of $f$ for terrestrial and fish meals, we intended to get free from this unknown variability. Results obtained from the feeds adulterated with MBM (with a bone content of $830 \mathrm{~g} \mathrm{~kg}^{-1}$, or a $f$ of 0.83) showed there was no overestimations of PAPs content as it had logically be expected 342 by using a formula with a $f$ fixed to 0.4 . Thus the proposed protocol succeeds to circumvent 343 this difficulty although the accurate reason is still poorly understood. It cannot be excluded that the sedimentation process or the Alizarin Red staining would account for this. Research 
345 is in progress for elucidating this and large-scale testing of the present protocol is needed 346 prior to any validation. 


\section{Acknowledgements}

348 We wish to thank Dr V. Planchon, from the Unit of Biometry, Data processing and

349 Agrometeorology of the Walloon Agricultural Research Centre, for her support in statistical

350 analyses. We also thank all the members of the CRL-AP team for their collaboration with

351 special attention to I. Fissiaux and C. Belinchón Crespo. 
353

354

355

356

357

358

359

360

361

362

363

364

365

366

367

368

369

370

371

372

373

374

375

376

\section{References}

European Commission. 2005. The TSE roadmap. Brussels: European Commission.

European Union. 2003. Directive EC/2003/126. Commission Directive of 23 December 2003 on the analytical method for the determination of constituents of animal origin for the official control of feedingstuffs. Off J Eur Comm L339, 78-84.

European Union. 2009. Regulation EC/2009/152. Commission Regulation of 27 January 2009 laying down the methods of sampling and analysis for the official control of feed. Off J Eur Comm L54, 1-130.

Feinberg M. 2006. Analyse des risques alimentaires. Paris : Lavoisier. Chapter 2, Composition des aliments; p. 45-100.

Gizzi G, von Holst C, Baeten V, Berben G, van Raamsdonk L. 2004. Determination of processed animal proteins, including meat and bone meal, in animal feed. J AOAC Int. 87 (6): 1334-1341.

Howard CV, Reed MG. 2005. Unbiased Stereology. 2nd ed. Oxon: Garland Science/BIOS Scientific Publishers.

ISO 5725-2. 1994. Accuracy (trueness and precision) of measurement methods and results - Part 2 : Basic method for the determination of repeatability and reproducibility of a standard measurement method. Cor 1:2002.

McClure D, Lee J-K. 2003. Computation of HORRAT values. J AOAC Int. 86 (5): 1056-1058.

Russ JC. 2005. Image Analysis of Food Microstructure. Boca Raton: CRC Press.

Veys P, Baeten V. 2007. CRL-AP Interlaboratory Study 2006 Final Report. Gembloux: CRAW.

Von Holst C, Alder L. 2005. Chromatographic-mass spectrometric food analysis for trace determination of pesticide residues, Comprehensive Analytical Chemistry XLIII. 
377 Almeria: Elsevier. Chapter 10, Proficiency tests in pesticide residue analysis; p. 439$378 \quad 469$. 
379

380

381

382

383

384

385

386

387

388

389

390

391

392

393

394

395

396

397

398

399

400

401

402

403 Figures (cf. separated files)

\section{Figure captions} over 20 other counts. (arrowheads) are visible.

Figure 1. Grid counting principle. (Red shapes: bone particles, grey shape: other particles, doted line shapes: particles outside the grid area and not considered for counting). Enlarged views illustrate the point counting principle: to each cross a zero-dimension point needs to be associated for avoiding overestimations (e.g. systematically the upper right corner of a cross). When the zero-dimension point hits a particle it is counted (green arrow), otherwise particles are not counted (red arrow). Counting result on this field is thus 23 bone counts

Figure 2. Predictable relative grid counting precision (expressed in \%) according to the number of fields and the number of total counts. Two cases are illustrated: with a mean number of counts per field of 25 (thin lines) and 50 (thick lines). The corresponding increase in numbers of total counts is indicated by dashed lines. $95 \%$ precision is achieved by obtaining 400 counts over either 8 fields $(\Delta)$ (with a mean number of counts per fields of 50 ) or 16 fields (O) (with a mean number of counts per field of 25).

Figure 3. Bovine bone particle from a sediment stained with Alizarin Red, mounted in Norland, photographed 12 months after mounting. The lacunae and the canaliculi

Figure 4. Bovine particle from a sediment stained with Alizarin Red, mounted in pure glycerol. (A) 3 min and (B) 120 min after mounting. The canaliculi are barely visible and the lacunae (arrowheads) fade over time due to glycerol penetration. 
Figure 1

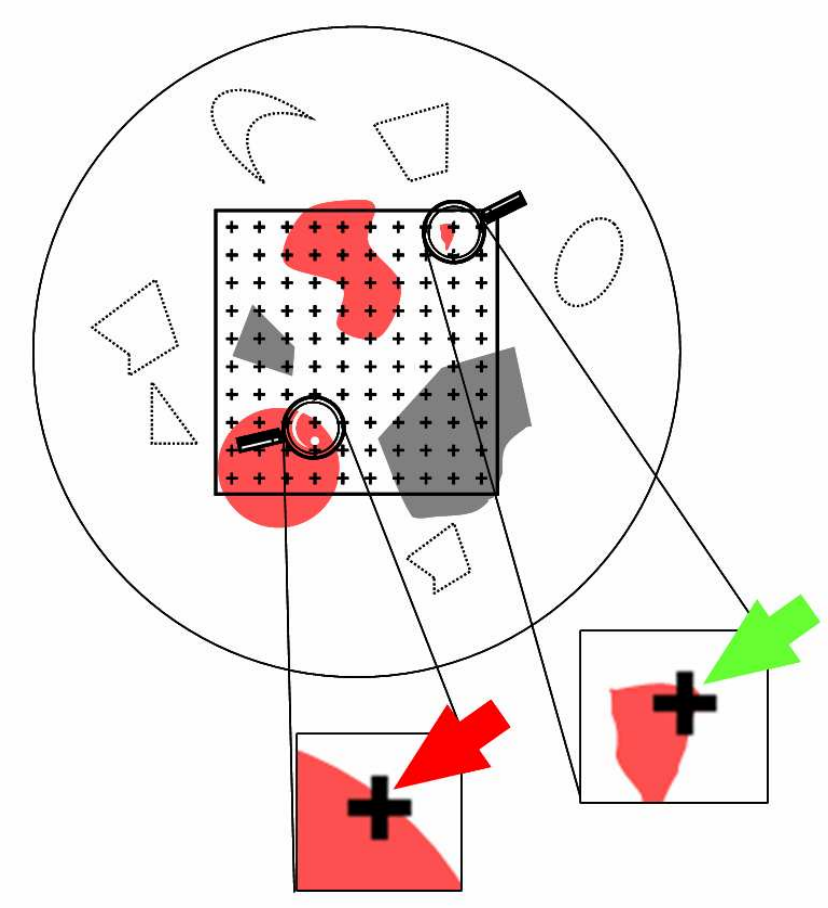

31

32
33

34

35

36

37

38

39

40

41

42

43

44

45

46

47

48

49

50

51

52

53

54

55

56

57

58

59

60

http://mc.manuscriptcentral.com/tfac Email: fac@tandf.co.uk 
Figure 2

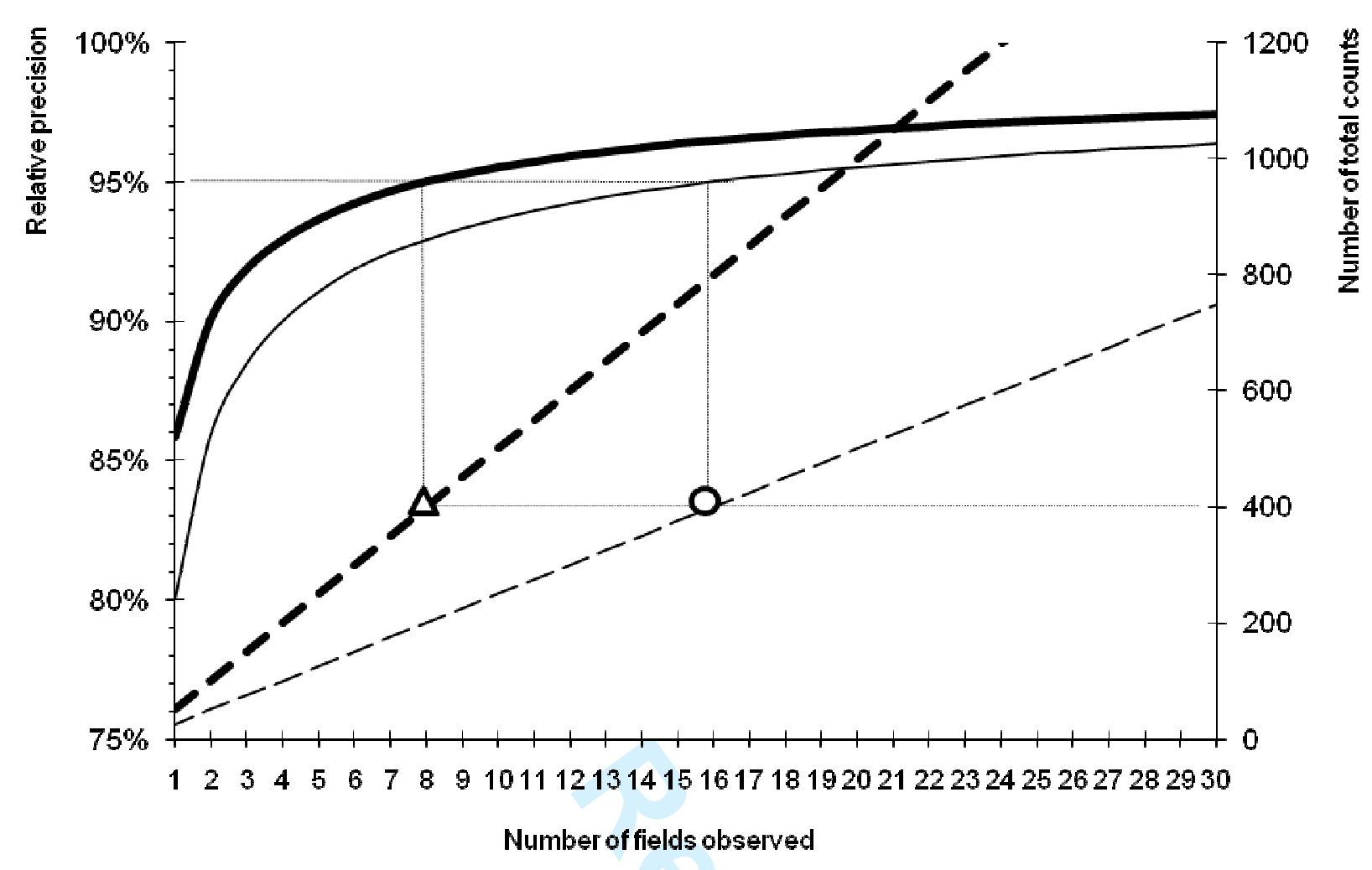




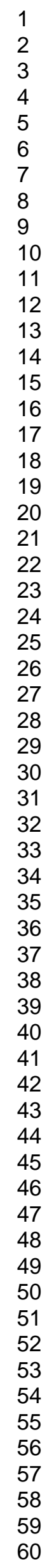

3

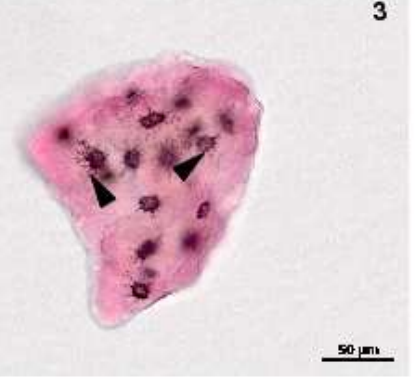

$209 \times 297 m m(72 \times 72$ DPI $)$

http://mc.manuscriptcentral.com/tfac Email: fac@tandf.co.uk 


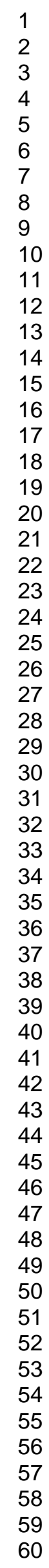

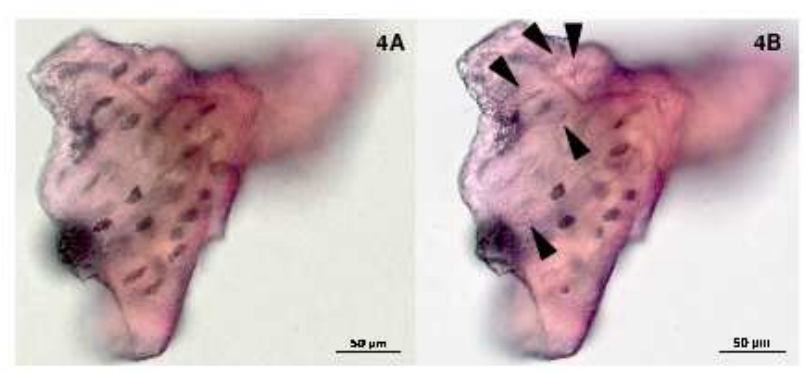

$209 \times 297 \mathrm{~mm}(72 \times 72 \mathrm{DPI})$

http://mc.manuscriptcentral.com/tfac Email: fac@tandf.co.uk 
Table 1. Quantification results of feed material adulterated with bovine MBM (at $5 \mathrm{~g} \mathrm{~kg}^{-1}$ and $10 \mathrm{~g} \mathrm{~kg}^{-1}$ ).

\section{$5 \mathrm{~g} \mathrm{~kg}^{-1}$ Bovine MBM}

\begin{tabular}{lcccccc}
\hline & & & \multicolumn{2}{c}{ analyst 1 } & \multicolumn{2}{c}{ analyst 2 } \\
\cline { 4 - 7 } Replicate & $\begin{array}{c}\text { Nb slides } \\
(<\mathbf{2 5 0} \boldsymbol{\mu m}+>\mathbf{2 5 0} \boldsymbol{\mu m})\end{array}$ & $\begin{array}{c}\text { Ss/W } \\
\left(\mathbf{m g ~ g}^{-1}\right)\end{array}$ & $\mathbf{C}$ & $\begin{array}{c}\text { MBM content } \\
\left(\mathbf{m g ~ g}^{-1}\right)\end{array}$ & $\mathbf{c}$ & $\begin{array}{c}\text { MBM content } \\
\left(\mathbf{m g ~ g}^{-1}\right)\end{array}$ \\
\hline 1 & $6(3+3)$ & 7.49 & 0.29 & $\mathbf{5 . 5 1}$ & 0.36 & $\mathbf{6 . 7 6}$ \\
2 & $6(3+3)$ & 7.59 & 0.26 & $\mathbf{5 . 0 0}$ & 0.24 & $\mathbf{4 . 4 6}$ \\
3 & $6(3+3)$ & 8.99 & 0.38 & $\mathbf{8 . 5 8}$ & 0.30 & $\mathbf{6 . 7 5}$ \\
4 & $6(3+3)$ & 7.60 & 0.30 & $\mathbf{5 . 7 1}$ & 0.36 & $\mathbf{6 . 8 4}$ \\
5 & $6(3+3)$ & 6.00 & 0.24 & $\mathbf{3 . 5 9}$ & 0.29 & $\mathbf{4 . 3 2}$ \\
\hline Mean & & 7.53 & 0.30 & $\mathbf{5 . 6 8}$ & 0.31 & $\mathbf{5 . 8 3}$ \\
SEM & & 0.47 & 0.02 & $\mathbf{0 . 8 1}$ & 0.02 & $\mathbf{0 . 5 9}$ \\
CV $(\%)$ & & 14.06 & 18.19 & $\mathbf{3 2 . 0 3}$ & 17.21 & $\mathbf{2 2 . 4 8}$
\end{tabular}

\section{$10 \mathrm{~g} \mathrm{~kg}^{-1}$ Bovine MBM}

\begin{tabular}{|c|c|c|c|c|c|c|}
\hline \multirow[b]{2}{*}{ Replicate } & \multirow[b]{2}{*}{$\begin{array}{c}\text { Nb slides } \\
(<250 \mu \mathrm{m}+>250 \mu \mathrm{m})\end{array}$} & \multirow[b]{2}{*}{$\begin{array}{c}\mathrm{Ss} / \mathrm{W} \\
\left(\mathrm{mg} \mathrm{g}^{-1}\right)\end{array}$} & \multicolumn{2}{|c|}{ analyst 1} & \multicolumn{2}{|r|}{ analyst 2} \\
\hline & & & C & $\begin{array}{l}\text { MBM content } \\
\left(\mathrm{mg} \mathrm{g}^{-1}\right)\end{array}$ & C & $\begin{array}{l}\text { MBM content } \\
\left(\mathrm{mg} \mathrm{g}^{-1}\right)\end{array}$ \\
\hline 1 & $6(3+3)$ & 7.88 & 0.55 & 10.89 & 0.34 & 6.79 \\
\hline 2 & $6(3+3)$ & 7.39 & 0.40 & 7.30 & 0.43 & 7.95 \\
\hline 3 & $6(3+3)$ & 9.16 & 0.47 & 10.69 & 0.27 & 6.29 \\
\hline 4 & $6(3+3)$ & 9.19 & 0.46 & 10.52 & 0.45 & 10.42 \\
\hline 5 & $6(3+3)$ & 7.77 & 0.50 & 9.64 & 0.46 & 9.01 \\
\hline Mean & & 8.28 & 0.47 & 9.81 & 0.39 & 8.09 \\
\hline SEM & & 0.38 & 0.03 & 0.66 & 0.04 & 0.75 \\
\hline $\mathrm{CV}(\%)$ & & 10.17 & 12.12 & 15.08 & 20.68 & 20.74 \\
\hline
\end{tabular}

For each slide, five random fields were observed. $\mathrm{Nb}=$ number; $\mathrm{Ss} / \mathrm{W}=$ stained sediment weight over weight of sample material used for the sedimentation; $\mathrm{C}=\mathrm{c}$ factor; $\mathrm{SEM}=$ standard error of mean; $\mathrm{CV}=$ coefficient of variation. 
Table 2. Quantification results of feed material adulterated with fishmeal (at $4 \mathrm{~g} \mathrm{~kg}^{-1}$ and $10 \mathrm{~g} \mathrm{~kg}^{-1}$ ).

\section{$4 \mathrm{~g} \mathrm{~kg}^{-1} \mathrm{Fish}$}

\begin{tabular}{|c|c|c|c|c|c|c|}
\hline \multirow[b]{2}{*}{ Replicate } & \multirow[b]{2}{*}{$\begin{array}{c}\text { Nb slides }{ }^{a} \\
(<250 \mu \mathrm{m}+>250 \mu \mathrm{m})\end{array}$} & \multirow[b]{2}{*}{$\begin{array}{c}\mathrm{Ss} / \mathrm{W} \\
\left(\mathrm{mg} \mathrm{g}^{-1}\right)\end{array}$} & \multicolumn{2}{|c|}{ analyst 1} & \multicolumn{2}{|c|}{ analyst 2} \\
\hline & & & d & $\begin{array}{l}\text { Fish content } \\
\left(\mathrm{mg} \mathrm{g}^{-1}\right)\end{array}$ & d & $\begin{array}{c}\text { Fish content } \\
\left(\mathrm{mg} \mathrm{g}^{-1}\right)\end{array}$ \\
\hline 1 & $10(6+4)$ & 15.73 & 0.02 & 0.35 & 0.02 & 0.31 \\
\hline 2 & $8(4+4)$ & 17.80 & 0.02 & 0.43 & 0.02 & 0.32 \\
\hline 3 & $8(4+4)$ & 16.27 & 0.03 & 0.44 & 0.01 & 0.20 \\
\hline 4 & $9(5+4)$ & 17.97 & 0.02 & 0.43 & 0.01 & 0.20 \\
\hline 5 & $8(4+4)$ & 16.19 & 0.04 & 0.59 & 0.01 & 0.21 \\
\hline Mean & & 16.79 & 0.03 & 4.48 & 0.01 & 2.46 \\
\hline SEM & & 0.46 & 0.00 & 0.39 & 0.00 & 0.28 \\
\hline CV $(\%)$ & & 6.08 & 21.09 & 19.35 & 25.71 & 25.12 \\
\hline
\end{tabular}

\section{$10 \mathrm{~g} \mathrm{~kg}^{-1} \mathrm{Fish}$}

\begin{tabular}{|c|c|c|c|c|c|c|}
\hline \multirow[b]{2}{*}{ Replicate } & \multirow[b]{2}{*}{$\begin{array}{c}\text { Nb slides }{ }^{\mathrm{a}} \\
(<250 \mu \mathrm{m}+>250 \mu \mathrm{m})\end{array}$} & \multirow[b]{2}{*}{$\begin{array}{c}\mathrm{Ss} / \mathrm{W} \\
\left(\mathrm{mg} \mathrm{g}^{-1}\right)\end{array}$} & \multicolumn{2}{|c|}{ analyst 1} & \multicolumn{2}{|c|}{ analyst 2} \\
\hline & & & d & $\begin{array}{l}\text { Fish content } \\
\left(\mathrm{mg} \mathrm{g}^{-1}\right)\end{array}$ & d & $\begin{array}{l}\text { Fish content } \\
\left(\mathrm{mg} \mathrm{g}^{-1}\right)\end{array}$ \\
\hline 1 & $11(6+5)$ & 16.18 & 0.04 & 7.04 & 0.05 & 7.99 \\
\hline 2 & $10(5+5)$ & 16.50 & 0.05 & 9.06 & 0.06 & 10.71 \\
\hline 3 & $11(7+4)$ & 17.49 & 0.05 & 9.44 & 0.03 & 5.82 \\
\hline 4 & $10(5+5)$ & 17.78 & 0.05 & 8.96 & 0.06 & 10.69 \\
\hline 5 & $11(6+5)$ & 16.46 & 0.05 & 7.93 & 0.06 & 10.48 \\
\hline Mean & & 16.88 & 0.05 & 8.49 & 0.05 & 9.14 \\
\hline SEM & & 0.32 & 0.00 & 0.44 & 0.01 & 0.97 \\
\hline CV(\%) & & 4.19 & 9.21 & 11.60 & 24.36 & 23.83 \\
\hline
\end{tabular}

${ }^{a}$ from the whole sediment

For each slide, 18 random fields were observed ( $=6$ fields/slide $\times 3$ repetitions). $\mathrm{Nb}=$ number; $\mathrm{Ss} / \mathrm{W}=$ stained sediment weight over weight of sample material used for the sedimentation; $\mathrm{c}=\mathrm{C}$ factor; SEM = standard error of mean; CV = coefficient of variation 
Table 3. Repeatability and intralaboratory reproducibility on the final estimation of MBM and fish content and the estimation of $c$ and $d$.

\begin{tabular}{rcccccccc} 
& \multicolumn{3}{c}{ MBM or Fish content } & & \multicolumn{3}{c}{ c or d } \\
\cline { 2 - 4 } \cline { 6 - 8 } & $\mathbf{P}$ & $\mathbf{r}$ & $\mathbf{R}$ & & $\mathbf{P}$ & $\mathbf{r}$ & $\mathbf{R}$ \\
\hline $5 \mathrm{~g} \mathrm{~kg}^{-1}$ MBM & 0.886 & 4.391 & $4.391^{\mathrm{a}}$ & & 0.710 & 0.148 & $0.148^{\mathrm{a}}$ \\
$10 \mathrm{~g} \mathrm{~kg}^{-1} \mathrm{MBM}$ & 0.124 & 4.380 & 5.166 & & 0.108 & 0.195 & 0.235 \\
& & & & & & & \\
$4 \mathrm{~g} \mathrm{~kg}^{-1}$ Fish & 0.003 & 2.084 & 4.363 & & 0.004 & 0.013 & 0.026 \\
$10 \mathrm{~g} \mathrm{~kg}^{-1}$ Fish & 0.559 & 4.682 & $4.682^{\mathrm{a}}$ & & 0.533 & 0.027 & $0.027^{\mathrm{a}}$
\end{tabular}

${ }^{a}$ values of $\mathrm{R}=\mathrm{r}$, because $\boldsymbol{s}_{A N A}^{2}=0$

$\mathrm{P}=$ Probability F-obs. $>\mathrm{F}$-crit.; $\mathrm{r}=$ repeatability (among analysts); $\mathrm{R}=$ intralaboratory reproducibility 
Table 4. Repeatability and intralaboratory reproducibility relative standard deviations on the final estimations on the MBM and fish content.

\begin{tabular}{rcc} 
& RSD $_{\mathrm{r}}(\%)$ & RSD $_{\mathrm{R}}(\%)$ \\
\hline $5 \mathrm{~g} \mathrm{~kg}^{-1} \mathrm{MBM}$ & 27.55 & $27.55^{\mathrm{a}}$ \\
$10 \mathrm{~g} \mathrm{~kg}^{-1} \mathrm{MBM}$ & 17.67 & 20.84 \\
$4 \mathrm{~g} \mathrm{~kg}^{-1}$ Fish & 21.69 & 45.42 \\
$10 \mathrm{~g} \mathrm{~kg}^{-1}$ Fish & 19.18 & $19.18^{\mathrm{a}}$ \\
& & \\
& \\
&
\end{tabular}

$R D_{r}=$ repeatability relative standard deviation; $R_{R} D_{R}=$ intralaboratory reproducibility relative standard deviation 